\title{
The Effect of Processing Parameters and Solid Concentration on the Microstructure and Pore Architecture of Gelatin-Chitosan Scaffolds Produced by Freeze-Drying
}

\author{
Daniel Enrique López Angulo ${ }^{a *}$, Paulo José do Amaral Sobral ${ }^{a}$ \\ ${ }^{a}$ Depto de Eng. de Alimentos - FZEA, University of São Paulo - USP, Av. Duque de Caxias Norte, 225, \\ CEP 13635-900, Pirassununga, SP, Brazil
}

Received: December 28, 2015; Revised: April 18, 2016; Accepted: June 5, 2016

\begin{abstract}
One of the main components for being successful in tissue engineering is developing a scaffold with an appropriate architecture for allow migration, cell proliferation, and differentiation. A gelatinchitosan scaffold by vacuum freeze-drying has been developed for tissue engineering applications. The effects of solid concentration and freezing processing on the scaffold morphology and porous size were investigated. As the chitosan content was increased the viscoelastic properties of pigskin gelatin was modified, the maximum G' values were lower than the values for pure gelatin solution, and the thermal transition points also occurred at lower temperatures, as well as a decrease of pore size tendency was observed and the scaffold visibly increased porosity, the structure scaffold was observed with an interconnected and more homogeneous pore matrix. The pore sizes become smaller and pore walls thinner, while interconnectivity increases along with declining pre-freezing temperature. The chitosan-gelatin scaffold will be a promising candidate in tissue engineering.
\end{abstract}

Keywords: tissue engineering, cell proliferation, interconnected pore matrix

\section{Introduction}

Tissue engineering is an emerging science enclosing such diverse fields as molecular biology and materials engineering. It attempts to develop biological substitutes for damaging organs and tissues ${ }^{1}$. Porous scaffolds have been extensively utilized in tissue engineering for playing an important role in manipulating cell function and guidance of new tissue formation as well as transporting nutrients and removing wastes ${ }^{2,3}$.

An ideal tissue engineered scaffold must have overall constructions, internal structures, surface properties, mechanical properties, and material properties to meet the requirements of host tissue ${ }^{4,5}$. Ideally, the porosity of the scaffolds, mean pore size and the pore structure should be appropriate for cell adhesion, proliferation, migration, differentiation and extracellular matrix regeneration. High porosity (generally greater than 90\%) and a large pore size (about 100-200 $\mu \mathrm{m}$ ) as well as highly interconnected pore structure are necessary for the transport of cells and metabolites ${ }^{6,7}$. The materials should be biocompatible without inflammation or toxicity in vivo and processed into 3D structure ${ }^{1,8}$.

Moreover, an ideal wound dressing scaffold should present several specific properties for the intended application, including capacity to absorb wound exudates, maintenance of the moisture, protection from secondary infection, provision of adequate gaseous exchange, provision of thermal insulation, free from particulate or toxic contaminants, mechanical durability, flexibility, and non toxicity ${ }^{9,10}$

Many polymers and biopolymers have been extensively investigated as potential materials for wound covering scaffold production. The use of natural biopolymers such as chitosan, collagen and gelatin in the construction of

\footnotetext{
* e-mail: daniel.lopez@usp.br
}

wound healing devices is quite attractive, mostly because of their biocompatibility, possibility of various chemical modifications, and relatively low cost of production (in many cases directly from renewable sources) ${ }^{11-15}$. Particularly, gelatin and chitosan are non-toxic, biodegradable, and biocompatible $^{14}$. This biopolymer has the capacity to form thermoreversible gel. Gelatin gel formation, at a molecular level, implicate a structural re-arrangement of the protein, involving the change from a messy stage to a more ordered one, formed by triple helix structures. The knowledge of the gel forming suspensions rheological properties by stationary and dynamic tests, is important for the design and processing of freezing gels.

Among several approach to produce biopolymers-based scaffolds, the freeze-drying processing is interesting because do not demand special equipment. With this processing, material pore characteristics such as size, homogeneity and orientation are dependent on ice crystal nucleation and growth, and can be controlled by modulating the freezing process $^{9-11}$. While pore size is largely governed by freezing temperature, pore homogeneity is achieved by controlling freezing rate and providing a uniform contact surface ${ }^{10,11}$.

In these contexts, aiming to develop a low cost scaffold, we are trying to develop a material based on blends of gelatin and chitosan by freeze-drying processing. We hypothesized that these biopolymers can have opposite charge depending of $\mathrm{pH}$ and this will contribute to a better material. Moreover, they can be modified and/or crosslinked by using a reactant as the glutaraldehyde. Thus, the objective of this work was focused on the study of the influence of gelatin:chitosan ratio, and on the effect of two freezing processing on scaffold microstructure (pore size range, average pore size). The effect of gelatin and chitosan concentration on the flow behavior and viscoelastic properties of gel forming suspensions was also studied. 


\section{Materials and methods}

\subsection{Materials}

A pig skin gelatin type-A was used (bloom 260; molecular weight $\sim 5.2 \times 10^{4} \mathrm{Da}$; moisture content $=9.98 \%$ ), supplied by Gelnex South America (Itá Santa Catarina, Brazil). Chitosan (derived from crab shell with minimum deacetylation degree of $85 \%$, MW: $2 \times 10^{5}$ ) was purchased from Sigma (St. Louis, MO, USA). Acetic acid (Sigma) and glycerol (Synth) were all chemical reagents of analytical grade.

\subsection{Fabrication of Porous Scaffolds.}

Blends of gelatin $(\mathrm{GE})$ and chitosan $(\mathrm{CH})$ were prepared by thorough mixing of gelatin $(2 \%)$ and chitosan (1\%) solutions in $0.05 \mathrm{M}$ acetic acid, with GE: $\mathrm{CH}$ ratios of 3:7, $5: 5,7: 3,9: 1$, under stirring with a magnetic bar, at $50^{\circ} \mathrm{C}$, for $2 \mathrm{~h}$., then the glycerol (gly) was added in $0,3 \%$, the $\mathrm{pH}$ of solutions was adjusted to 5 . The solution blends were then poured into a glass petri dish and then: a) freezing in refrigerator at $-27^{\circ} \mathrm{C}$ (for evaluating the effect of the solid concentration), and $\mathrm{b}$ ) the glass petri was left 2 hours in liquid nitrogen system chamber $-190^{\circ} \mathrm{C}$, and then was kept in a refrigerator $-27^{\circ} \mathrm{C}$ until the lyophilization (for evaluating the effect of freezing rate it was utilized two temperatures). After that, these products were submitted to the first freeze-drying at $-55^{\circ} \mathrm{C}$ for $18 \mathrm{~h}$. reaching a sponge-like material (Figure 1).

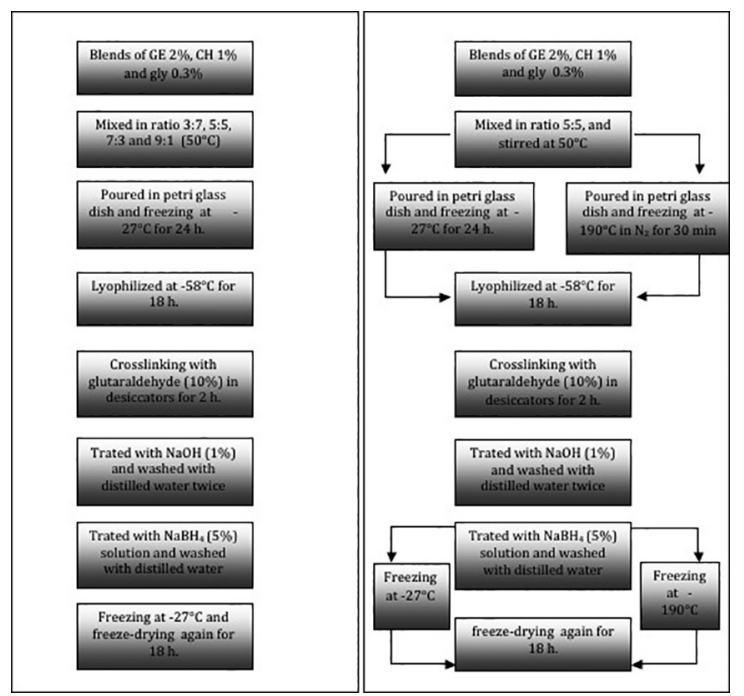

Figure 1: Diagram of the steps of obtaining scaffolds, left (effect of the solid concentration) and right (effect of freezing rate).

To crosslinking the GE: $\mathrm{CH}$, the obtained sponge was placed inside desiccators containing glutaraldehyde (10\%) in $200 \mathrm{ml}$ ethanol $(90 \%)$ during $2 \mathrm{~h}$. Then, the sponge was immersed in $\mathrm{NaOH}$ solution (1\%) and washed with distilled water twice, and treated with a $\mathrm{NaBH}_{4}(5 \% \mathrm{w} / \mathrm{v})$ solution to block residual aldehyde groups. After that, the scaffolds were conveniently washed with distilled water and re-submitted to freezing, followed by the second freeze-drying for $18 \mathrm{~h}$. The best composition was selected for further characterization; the effect of freezing rate.

\subsection{Rheological measurements}

The scaffolds forming solutions were analyzed to determine it rheological and visco-elastic properties. Rheological tests were carried out in a rheometer (AR2000 Advanced Rheometer; TA Instruments, New Castle, DE, USA) using a cone and plate sensor geometry (cone angle $4^{\circ}, 60 \mathrm{~mm}$ diameter). This equipment controlled the temperature with a peltier system. The results were analyzed using the software Rheology Advantage Data Analysis V.5.3.1 (TA Instruments).

\subsubsection{Dynamic tests}

For the dynamic tests, the extent of the linear viscoelastic region was determined by performing a strain (0-20\%) sweep in gel forming solutions both as a gel $\left(5^{\circ} \mathrm{C}\right)$ and as a sol $\left(30^{\circ} \mathrm{C}\right)$, in all cases at $1 \mathrm{~Hz}$ of frequency. Thus, according to the results of these tests, the strain value used for all following dynamic tests was fixed at $4 \%$, within the linear viscoelastic domain. The viscoelastic parameters determined in these trials were the storage or elastic modulus $\left(G^{\prime}\right)$ and the loss or viscous modulus $\left(\mathrm{G}^{\prime \prime}\right)^{16}$.

\subsubsection{Temperature sweep tests}

Early, the scaffold forming solutions were heated up to $50^{\circ} \mathrm{C}$ without a predestined heating rate program, starting the tests when that measurement temperature was attained ${ }^{16}$. The measures were separated in two parts, first, the sample was cooled down from 50 to $5^{\circ} \mathrm{C}$, remaining at this latter temperature for $5 \mathrm{~min}$., and second heating up the sample to $50^{\circ} \mathrm{C}$, at heating rate of $2^{\circ} \mathrm{C} / \mathrm{min}$. G' and $\mathrm{G}$ " values as a function of temperature were used to establish the following parameters: gelling $\left(\mathrm{T}_{\text {sol-gel }}\right)$ and melting $\left(\mathrm{T}_{\text {gel-sol }}\right)$ temperatures, calculated as the temperature where $G$ ' changed drastically as an inflexion point; and the viscoelastic moduli ( $\mathrm{G}^{\prime}$ and G') of the gel, calculated at $5^{\circ} \mathrm{C}^{17}$.

\subsection{Scanning Electron Microscopy}

The surface morphology, structural integrity and interconnectivity of the pores in the scaffold were observed using Scanning Electron Microscopy (Hitachi TM 3000, Japan) at a magnification of 100x. The sample was placed on double sided carbon tape in a vacuum chamber prior to measurement. The surface of the samples was scanned at $15 \mathrm{kV}$, without previous treatment ${ }^{18}$. The pore sizes of the scaffolds were measured using image visualization software (Image J 1.45s, NIH Image, USA). The values were expressed as the mean \pm standard error.

\subsection{Statistical analysis}

Statistical analysis and interpretation of all results was done by using GraphPad Prism version 6.00 for Windows (GraphPad Software, San Diego, California, USA). One way ANOVA with Bonferroni posttest was performed, to obtain the variance between and within all treatments. $P$-values less than 0.05 denoted statistical significance. 


\section{Results and discussions}

\subsection{Scanning temperature in dynamic rheological tests.}

Rheology provides information about the polymer flow properties, including the changes in the behaviour of the polymer when it subjected to a stress with variation in temperature. The storage and loss modulus in case of viscoelastic solids is the measure of stored energy, which represents their elastic portion, and the energy dissipated in the form of heat, representing the viscous portion, respectively ${ }^{19}$.

The preliminary tests allowed to determine the conditions of tests inside the linear viscoelastic domain: frequency $=1 \mathrm{~Hz}$, and strain amplitude $=0-20 \%$. Thus, scanning temperature in dynamic rheological tests was carried out (Figure 2), allowing the determination of both moduli (G'and G"), which had higher values at low than at higher temperatures. Between these two domains, an inflexion was observed in both moduli. These behaviors are typical of physical gels presenting a sol-gel $\left(\mathrm{T}_{\text {sol-ge }}\right)$ and a gel-sol ( $\left.\mathrm{T}_{\text {gel-sol }}\right)$ transition. The result shown, when the systems showed a gel character, it was also observed that the stiffness (elastic character) increased with gelatin concentration in the blend. Similar profiles have been observed by several authors in gelatin based systems ${ }^{17,20,21}$. When the chitosan concentration was increased, the viscoelastic properties of pig gelatin was modified, the maximum G'values were lower than the values for pure gelatin solution, and the thermal transition points also occurred at lower temperatures. A decrease in percentage renaturation of food grade gelatin by incorporation of chitosan has been previously reported ${ }^{22}$.
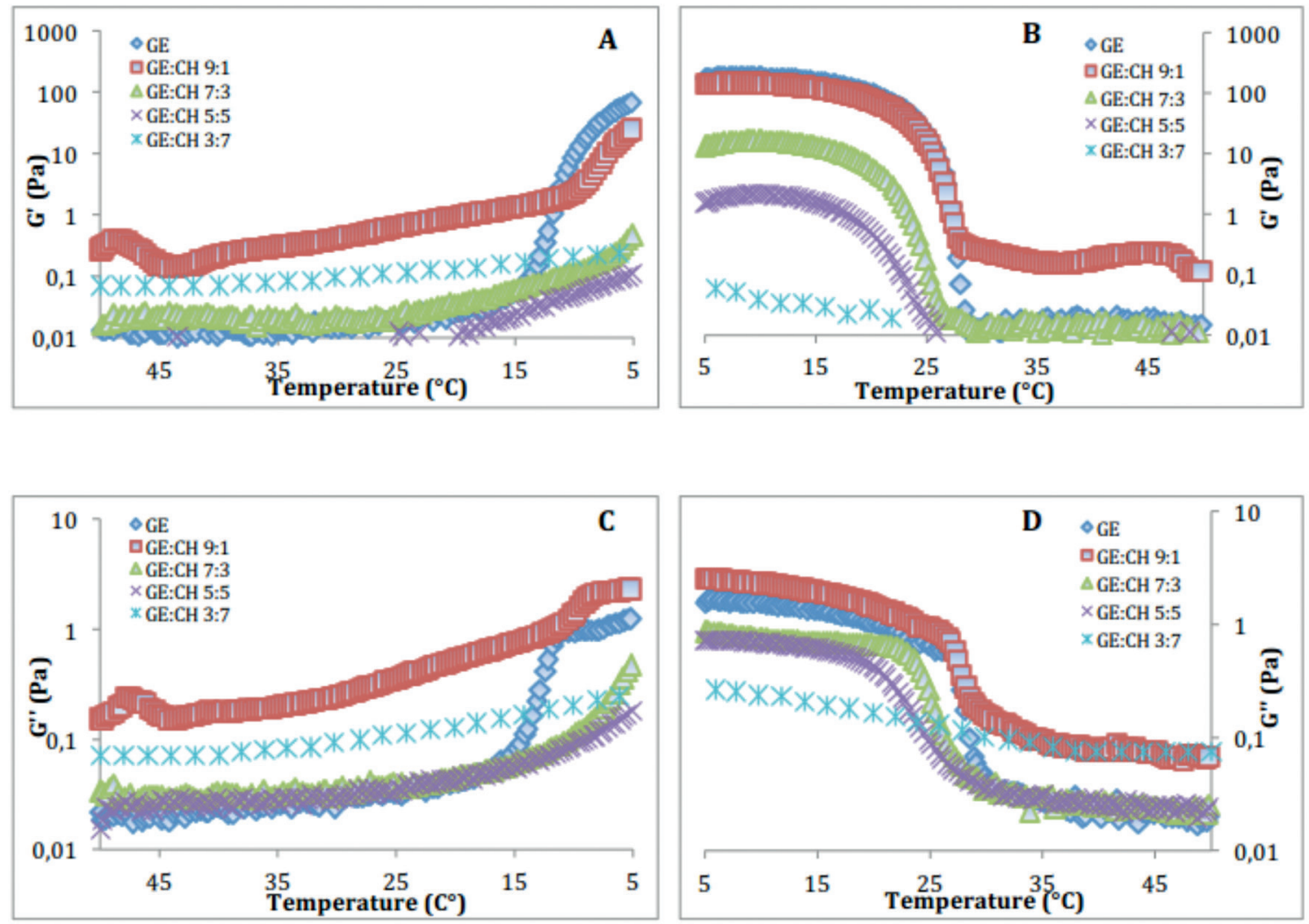

Figure 2: Storage (G') and loss (G”) moduli of scaffold based on blends of gelatin and chitosan as a function of temperature. (A and C) cooling; (B and D) heating, both at $2^{\circ} \mathrm{C} / \mathrm{min}$.
The temperatures of the sol-gel and gel-sol transitions, fitted as the temperature where the peak of the curve of the first derivative of G' occurred, were affected by the chitosan concentration. The increase in the chitosan concentration in the blend, as it was noted above, caused an intense reduction (46.4\%) in the $\mathrm{T}_{\text {sol-gel }}$, which decreased from around $15.3^{\circ} \mathrm{C}$ to $8.2^{\circ} \mathrm{C}$, whereas the $\mathrm{T}_{\text {gel-sol }}$ decreased $(24.3 \%)$ from around $28.8^{\circ} \mathrm{C}$ to about $21.8^{\circ} \mathrm{C}$ (Table 1 ). These phenomena may well be related with the processes involved in the coil-helix/ helix-coil transition. The gelatin triple helix formation (coilhelix transition) is a slow process, which continues almost indefinitely, while the dissociation (helix-coil transition) of the triple helix is an equilibrium process linked with the transition temperature ${ }^{23}$. Therefore, this is indicative of a pronounced loss of the gelatin's ability to refold into triplehelix chains in the presence of chitosan. Adding chitosan at the higher proportion led to a substantial increase in the viscous modulus (G") during cooling.

It is interesting to analyze the isoelectric point of the gelatin in terms of molecular interactions with chitosan. The gelatin used in this study is type-A, therefore the isoelectric point should be around $\mathrm{pH} 8-9$, further solutions were adjusted to $\mathrm{pH} 5$, therefore gelatin below its isoelectric point it is positively charged. Also, chitosan is a cationic polysaccharide, where the interactions between gelatin and chitosan are produced by both electrostatic and hydrogen bonding ${ }^{24}$. The latter occur extensively between the - $\mathrm{COOH}$, $-\mathrm{NH} 2$, and - $\mathrm{OH}$ groups on the amino acids in the gelatin and the $-\mathrm{OH}$ and $-\mathrm{NH}_{2}$ groups on the

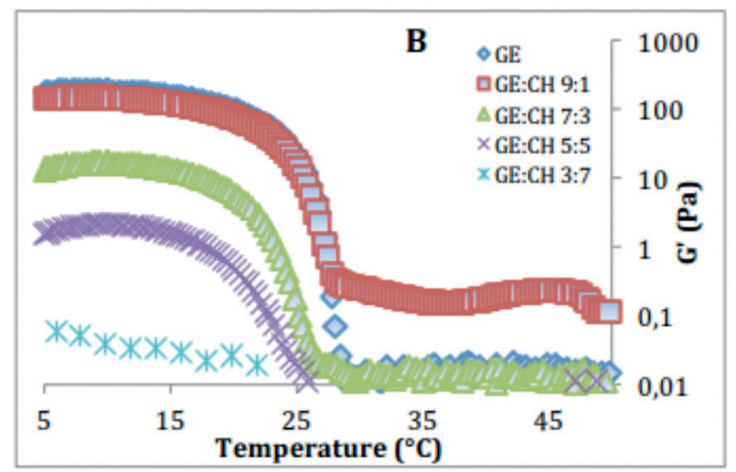


Table 1: Transition temperatures $\mathrm{T}_{\text {sol-gel }}$ and $\mathrm{T}_{\text {gel-sol }}$ of gel forming solutions based on different rate of gelatin and chitosan.

\begin{tabular}{lcc}
\hline GE-CH ratio & $\mathrm{T}_{\text {sol-gel }}\left({ }^{\circ} \mathrm{C}\right)$ & $\mathrm{T}_{\text {gel-sol }}\left({ }^{\circ} \mathrm{C}\right)$ \\
\hline $10: 0$ & $15.3_{\mathrm{a}} \pm 0.07$ & $28.8^{\mathrm{a}} \pm 0.14$ \\
$9: 1$ & $11.9_{\mathrm{b}} \pm 0.04$ & $28.3^{\mathrm{a}} \pm 0.09$ \\
$7: 3$ & $9.1_{\mathrm{c}} \pm 0.01$ & $25.8^{\mathrm{b}} \pm 0.14$ \\
$5: 5$ & $8.8_{\mathrm{d}} \pm 0.06$ & $25.4^{\mathrm{b}} \pm 0.14$ \\
$3: 7$ & $8.2_{\mathrm{e}} \pm 0.06$ & $21.8^{\mathrm{c}} \pm 0.21$ \\
\hline
\end{tabular}

Different letters indicate significant differences $(\mathrm{p}<0.05)$.

chitosan, and are particularly notable at low temperatures. The chitosan structure is formed by units of glucosamine and $\mathrm{N}$-acetyl D-glucosamine linked by $\beta$ - $(1 \rightarrow 4)$ where the deacetylation degree is the percentage of amino groups that remaining free in the chitosan molecule, in fact, a high amount of options is presented to generate electrostatic interactions with pig gelatin which is more polar. Due to the acidic $\mathrm{pH}$ of the suspensions, these amine residues of chitosan are protonated $\left(\mathrm{NH}_{3}^{+}\right)$and could form electrostatic interactions preferably with acid residues of gelatin (COO- from Glutamine and Aspartic acid), they will also form bridges with polar residues above. However, the amount of formed interactions will depend on the degree of exposure of residues of the protein to interact with the chitosan and that will be determined by the degree of unfolding of the protein, as well as by the relative abundance of acid residues in protein versus polar residues and the stoichiometry of the interaction.

\subsection{Effect of biopolymers ratios on morphology}

The average thickness of GE:CH scaffold was between 1.4-1.7 mm (Table 2). As pig gelatin being a macromolecules and forms cross-linkage with chitosan molecules through hydrogen bonding and electrostatic interaction, the highest proportion of gelatin it had increased the thickness of scaffold. The porous microstructure of the scaffolds has a remarkable influence on the cell intrusion, proliferation and function, when tissue engineering uses are envisioned ${ }^{14}$. Because of that, this structure must be well controlled. Then, the $\mathrm{GE}: \mathrm{CH}$ ratio was evaluated and optimized through the their intrinsic microstructure and porous size observation. It can be observed in Figure 3 that the chitosan have an important effect on material microstructure allowing the formation of sponge type structure.

Table 2: Effect of GE:CH ratio on the porous size and porous size range of the scaffolds.

\begin{tabular}{lccc}
\hline GE-CH & Pore size $(\mu \mathrm{m})$ & $\begin{array}{c}\text { Pore size range } \\
(\mu \mathrm{m})\end{array}$ & $\begin{array}{c}\text { Scaffolds } \\
\text { Thickness } \\
(\mathrm{mm})\end{array}$ \\
\hline $3: 7$ & $178.5^{\mathrm{a}} \pm 69.1$ & $132-311$ & $1.46^{\mathrm{a}} \pm 0.03$ \\
$5: 5$ & $198.3^{\mathrm{ab}} \pm 47.9$ & $162-296$ & $1.40^{\mathrm{a}} \pm 0.02$ \\
$7: 3$ & $202.8^{\mathrm{b}} \pm 64.1$ & $163-338$ & $1.70^{\mathrm{b}} \pm 0.04$ \\
$9: 1$ & $192.5^{\mathrm{ab}} \pm 49.8$ & $160-393$ & $1.66^{\mathrm{b}} \pm 0.03$ \\
\hline
\end{tabular}

Different letters indicate significant differences $(\mathrm{p}<0.05)$
Then, scaffold fabricated with higher proportion of gelatin (GE:CH=9:1, Figure 3a) have irregular pore structure without a well visible porous networking structure. The pore walls were thicker with very few holes in the pore walls, which may indicate that the interconnectivity of the scaffolds could be poor. This effect could difficult fluid exchange and growing of native tissue. Similar structure was observed for $\mathrm{GE}: \mathrm{CH}=7: 3$ (Figure $3 \mathrm{~b}$ ) ratio material. As the chitosan content was increased, a more homogeneous structure can be observed, with some tendency for lower porous size formation. Moreover, these scaffolds visibly presented increased porosity, and with matrix with an interconnected and more homogeneous pore structure (GE:CH=5:5, Figure 3c; GE: $\mathrm{CH}=3: 7$, Figure 3d). Very thin walls can be observed for equal proportion of biopolymers, but with less homogeneous porous size distribution $(\mathrm{GE}: \mathrm{CH}=5: 5$, Figure $3 \mathrm{c}$ ). This increasing in homogeneity of porous size allow more hollow space, meaning that more fluid and liquid component could be introduced to the scaffolds.

The porous size was calculated after image treatments allowing calculation of data presented at Table 2, where it can be observed that, in overall, the pore size varied between 132 and $393 \mu \mathrm{m}$, for all formulations. The smallest and the largest $(P<0.05)$ average pore size was $179 \mu \mathrm{m}$, for scaffolds produced with $\mathrm{GE}: \mathrm{CH}=3: 7$ ratio, and $203 \mu \mathrm{m}$, for $\mathrm{GE}: \mathrm{CH}=$ $7: 3$, respectively (Table 2 ). These results suggested that the proportion of $\mathrm{GE}$ and $\mathrm{CH}$ was directly related to the pore size.

Previous research ${ }^{25}$ reported that the mean pore size of collagen based scaffolds was affected by the viscosity of the material solution. Increasing the chitosan content raises the viscosity of the polymeric solution, reducing the density of the complex solution and leads to an increased porosity ${ }^{26}$ after freeze-drying. The viscosity of the solution is large $(>2 \%)$, which is unfavorable to the water and the molecular chains moving in the solution. Therefore, the number of ice nuclei in the solution with high concentration is smaller and more difficult to grow larger than that of the low concentration one $^{26}$. So, the pore size is inversely proportional to the concentration of the scaffolds ${ }^{27}$. All scaffolds obtained in this work were freeze-dried at the same time and under the same conditions; thus, the difference in the pore structure is associated only with the GE: $\mathrm{CH}$ ratios.

Thus, considering these quali-quantitative results of SEM, it could be concluded that GE: $\mathrm{CH}$ 5:5 formulation were with good pore size and porosity, which indicated that the sponge scaffold meet the basic requirements as tissue engineering material. However, the structure scaffold can even be improved by altering the conditions of freezing before freeze-drying; the effect of freezing rate is an important factor to be evaluated in terms of its interconnected porous structure.

\subsection{Effect of freezing processing on morphology}

In these essays, the materials were produced by freezedrying after freezing at $-190^{\circ} \mathrm{C}$ (by quenching in liquid nitrogen). Then, these scaffolds were cryofractured for analysis of internal microstructure beside the surface structure. The results of these analyses are presented at Figure 4. These 

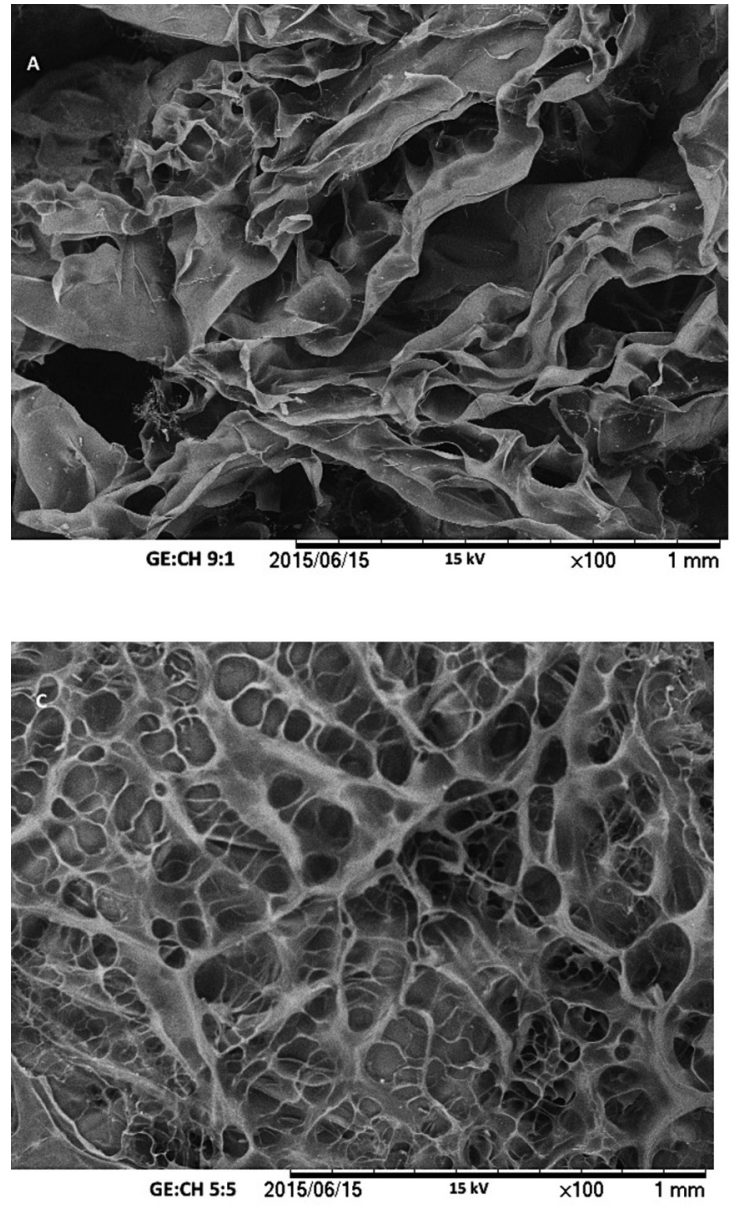
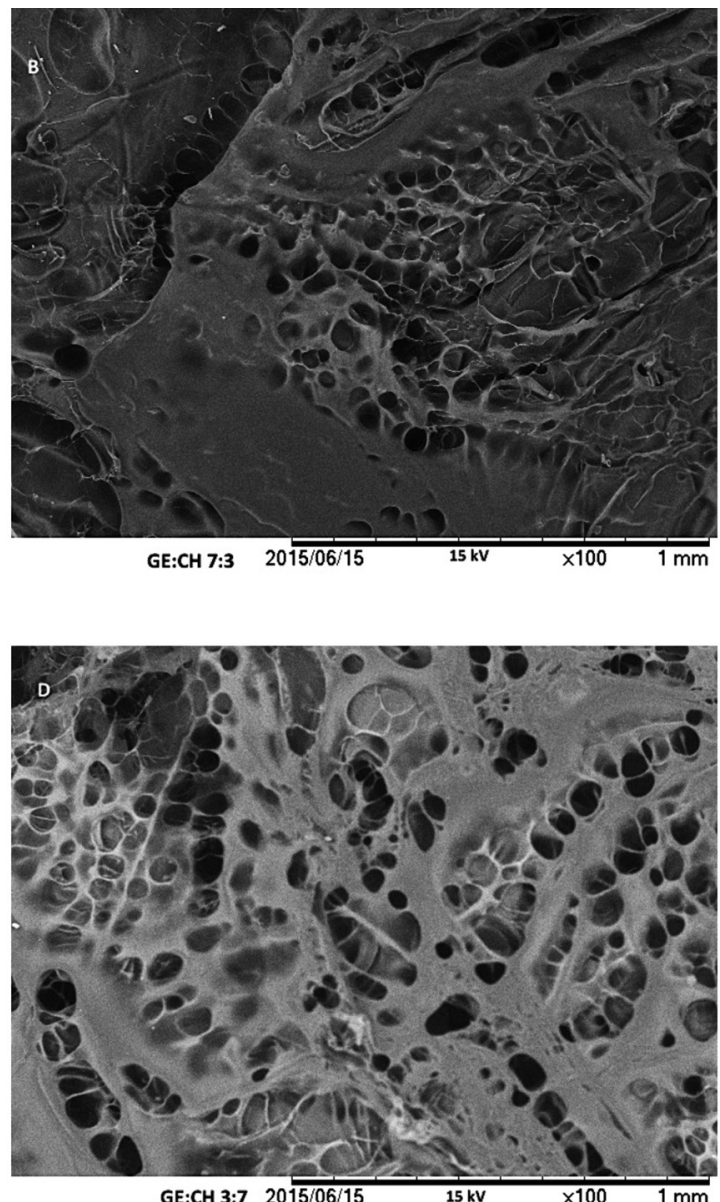

GE:CH $3: 7 \quad 2015 / 06 / 15$

Figure 3: Superficial SEM Images of scaffolds obtained with different GE:CH ratios: 9:1 (A), 7:3 (B), 5:5 (C) and 3:7 (D).

results indicated that freezing processing had an evident effect on the pore size and distribution in these scaffolds, due to the difference in the growth velocity of ice crystals formed during freezing of materials. Scaffolds prepared by quenching samples in liquid nitrogen $\left(-190^{\circ} \mathrm{C}\right.$, Figure $4 \mathrm{c}, \mathrm{d}$ ) exhibited smaller pores with a uniform distribution and with pore walls thinner, whereas the scaffolds frozen at higher temperatures $\left(-27^{\circ} \mathrm{C}\right.$, Figure $\left.4 \mathrm{a}, \mathrm{b}\right)$ exhibited a poor porous microstructure with heterogeneous and big size pores. These results agree with those reported by ${ }^{28}$. After ice crystals sublimation during freeze-drying, the scaffold structure contains pores that correspond to the size and shape of the ice crystals ${ }^{29}$.

Analysis of the images of surface structure allowed calculation of the average pores size: $119.2 \pm 38.1 \mu \mathrm{m}$, for material frozen at $-190^{\circ} \mathrm{C}$, and $196.8 \pm 36.9$, for the specimen frozen at $-27^{\circ} \mathrm{C}$. Both pore size ranges are within the ideally expected for the transport of cells and metabolites in this kind of material ${ }^{6,7}$, however, the cross-sectional image shows a much more homogeneous structure and arranged in layers to the material obtained after freezing at lower temperature.

It is important to consider how variations in pore architecture affect cell-material interactions. Experimental studies have led to the determination of a characteristic interaction parameter, by careful analysis, it can be shown that two matrices with identical chemistries but differing pore diameters have vastly different abilities to provide for cellular attachment. For example, scaffolds containing pores of $300 \mathrm{~mm}$ have a much lower internal surface area than matrices with pore diameters of less than $50 \mathrm{~mm}$ and, as such, bind a much lower number of cells in the matrix. Because of the low cellular infiltration, tissue formation in these constructs is slow and in certain cases inhibited due to lack of interactions between cells ${ }^{30}$. In general, research supports that pores larger than $10 \mathrm{~mm}$ (the average cell diameter) will permit cell infiltration ${ }^{31}$. In terms of successful histogenesis, both pore size and the degree of porosity are tissue and scaffold specific. For example, in vivo osteogenesis occurs in biomaterials of high porosity $(>70 \%)$ with average pore sizes $>300 \mathrm{~mm}^{32}$. However, in skin regeneration, successful scaffolds need only to exhibit pore sizes of $20-125 \mathrm{~mm}^{30}$. Therefore, in this study the proposed material according to its porosity and average pore diameter, could be a good candidate for use in tissue regeneration as skin and cartilage.

\section{Conclusions}

The increase in the chitosan concentration in the blend caused an intense reduction in the $\mathrm{T}_{\text {sol-gel }}$, and $\mathrm{T}_{\text {gel-sol }}$ this is indicative of a marked loss of the gelatin's ability to refold into 

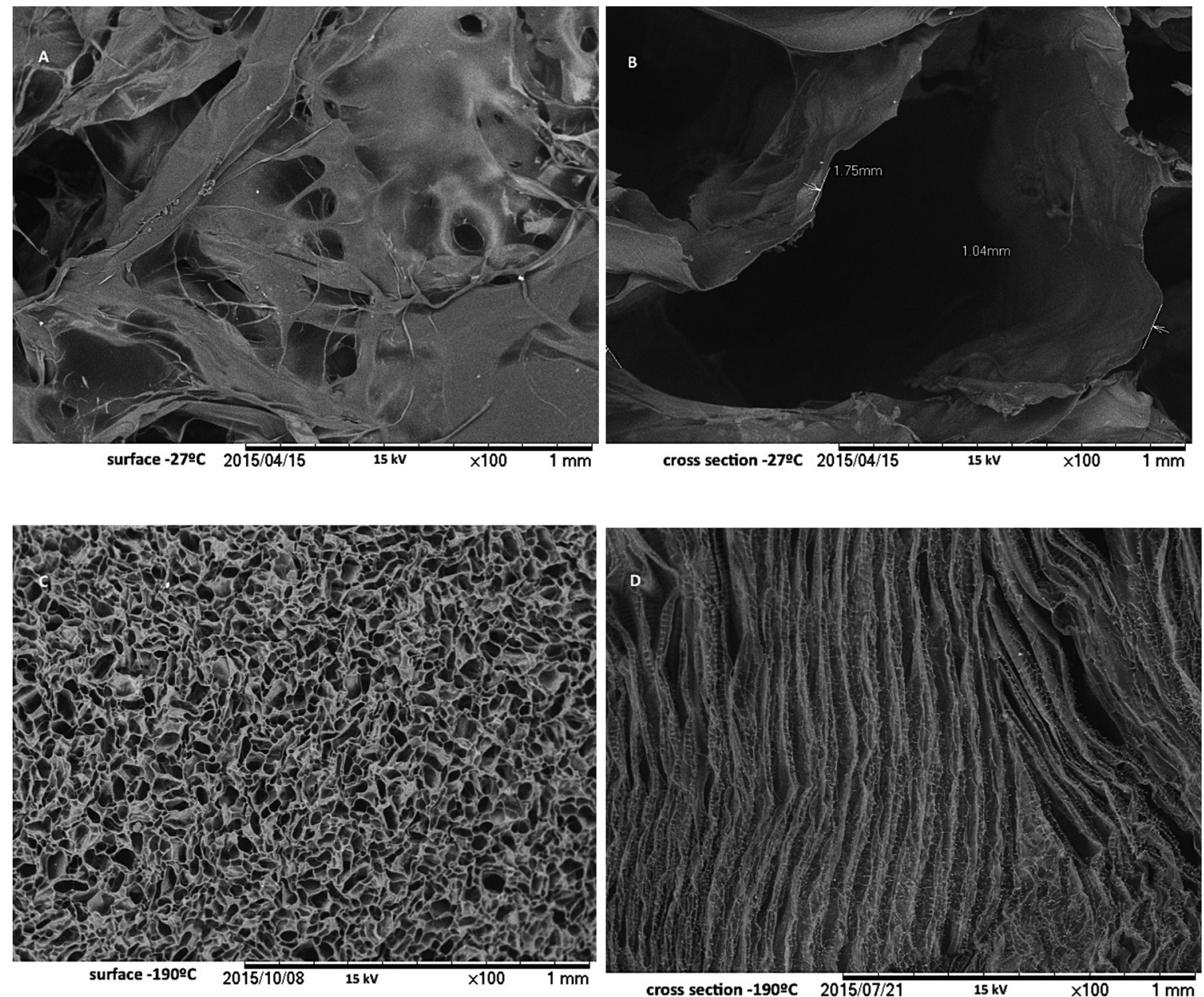

Figure 4: Surface (left) and cross-section (right) images of scaffolds frozen at $-27^{\circ} \mathrm{C}(\mathrm{a}, \mathrm{b})$ and $-190^{\circ} \mathrm{C}(\mathrm{c}, \mathrm{d})$ measured by SEM .

triple-helix chains in the presence of chitosan. Morphology of the pigskin gelatin and chitosan scaffolds prepared by freeze-drying technique and different solid proportion and freezing rate was investigated. The incorporation of chitosan improved the pore structure and size uniformity in superficial area of the scaffolds. The pore sizes becomes smaller and pore walls thinner, while an improved of interconnectivity was observed with declining pre-freezing temperature. It has the porous structure, surface morphology, could be favorable to penetrate nutrients, export metabolic substances and leave new spaces for cells to fill in and produce new intercellular matrix. Finally, the study underscores gelatin-chitosan composite as a potential and promissory scaffold material for skin regeneration.

\section{Acknowledgments}

The authors would like to thank at the Brazilian National Council for Scientific and Technological Development (CNPq) and TWAS, the academy of sciences for the developing world, for the research grants (190232/2014-5 CNPq/ TWAS-FR: 3240279900). And to the Food's Laboratory of Sao Paulo University.

\section{References}

1. Teimouri A, Azadi M, Emadi R, Lari J, Chermahini AN. Preparation, characterization, degradation and biocompatibility of different silk fibroin based composite scaffolds prepared by freeze-drying method for tissue engineering application. Polymer Degradation and Stability. 2015;121:18-29.

2. Chen G, Ushida T, Tateishi T. Scaffold design for tissue engineering. Macromolecular Bioscience. 2002;2(2):67-77.

3. Zmora S, Glicklis R, Cohen S. Tailoring the pore architecture in 3-D alginate scaffolds by controlling the freezing regime during fabrication. Biomaterials. 2002;23(20):4087-4094.

4. Sengers BG, Taylor M, Please CP, Oreffo ROC. Computational modelling of cell spreading and tissue regeneration in porous scaffolds. Biomaterials. 2007;28(10):1926-1940.

5. Chen M, Zuo B. Summarization of cartilage scaffolds material for tissue engineer. Modern Silk Science and Technology. 2011;26(3):110-113.

6. Freyman TM, Yannas IV, Gibson LJ. Cellular materials as porous scaffolds for tissue engineering. Progress in Materials Science. 2001;46(3-4):273-282.

7. Geiger M, Friess W. Collagen sponge implants - applications, characteristics and evaluation: part II. Pharmaceutical Technology Europe. 2002;14(4):58-66. 
8. Yang S, Leong KF, Du Z, Chua CK. The design of scaffolds for use in tissue engineering. Part I. Traditional factors. Tissue Engineering. 2001;7(6):678-689.

9. Purna et . Collagen based dressings-a review. Burns. 2000;26(1):54-62.

10. Haugh MG, Murphy CM, O’Brien FJ. Novel freeze-drying methods to produce a range of collagen-glycosaminoglycan scaffolds with tailored mean pore sizes. Tissue Engineering: Part C: Methods. 2009;16(5):887-894.

11. Jayakumar R, Prabaharan M, Sudheesh Kumar PT, Nair SV, Tamura H. Biomaterials based on chitin and chitosan in wound dressing applications. Biotechnology Advances. 2011;29(3):322-337.

12. Busilacchi A, Gigante A, Mattioli-Belmonte M, Manzotti S, Muzzarelli RA. Chitosan stabilizes platelet growth factors and modulates stem cell differentiation toward tissue regeneration. Carbohydrate Polymers. 2013;98(1):665-676.

13. Hoyer B, Bernhardt A, Heinemann S, Stachel I, Meyer M, Gelinsky M. Biomimetically mineralized salmon collagen scaffolds for application in bone tissue engineering. Biomacromolecules. 2012;13(4):1059-1066.

14. Renó CO, Lima BFAS, Sousa E, Bertran CA, Motisuke M. Scaffolds of calcium phosphate cement containing chitosan and gelatin. Materials Research. 2013;16(6):1362-1365.

15. Yang C, Fang C. Microporous nano-hydroxyapatite/collagen/ phosphatidylserine scaffolds embedding collagen microparticles for controlled drug delivery in bone tissue engineering. Materials Research. 2015;18(5):1077-1081.

16. Moraes ICF, Carvalho RA, Bittante AMQB, Solorza-Feria J, Sobral PJA. Film forming solutions based on gelatin and poly(vinyl alcohol) blends: Thermal and rheological characterizations. Journal of Food Engineering. 2009;95(4):588-596.

17. Gómez-Guillén MC, Ihl M, Bifani V, Silva A, Montero P. Edible films made from tuna-fish gelatin with antioxidant extracts of two different murta ecotypes leaves (Ugni molinae Turcz). Food Hydrocolloids. 2007;21(7):1133-1143.

18. Jorge MFC, Alexandre EMC, Flaker CHC, Bittante AMQB, Sobral PJA. Biodegradable Films Based on Gelatin and Montmorillonite Produced by Spreading. International Journal of Polymer Science. 2015, ID 806791, 9p.

19. Meyers MA, Chawla KK. Mechanical behavior of materials. New York: Cambridge University Press; 1999. 882p.

20. Van den Bulcke AI, Bogdanov B, De Rooze N, Schacht EH, Cornelissen M, Berghmans H. Structural and rheological properties of methacrylamide modified gelatin hydrogels. Biomacromolecules. 2000;1(1):31-38.
21. Cho SM, Gu YS, Kim SB. Extracting optimization and physical properties of yellowfin tuna (Thunnus albacares) skin gelatin compared to mammalian gelatins. Food Hydrocolloids. 2005;19(2):221-229.

22. Arvanitoyannis IS. Formation and properties of collagen and gelatin films and coatings. In: Gennadios A, ed. Protein-based Films and Coatings. Boca Raton: CRC Press; 2002. p.275-304.

23. Fitzsimons SM, Mulvihill DM, Morris ER. Segregative interactions between gelatin and polymerized whey protein. Food Hydrocolloids. 2008;22(3):485-492.

24. Taravel MN, Domard A. Collagen and its interaction with chitosan. II. Influence of the physicochemical characteristics of collagen. Biomaterials. 1995;16(11):865-871.

25. Doillon CJ, Whyne CF, Brandwein S, Silver FH. Collagen-based wound dressings: Control of the pore structure and morphology. Journal of Biomedical Materials Research. 1986;20(8):1219-1228.

26. O’Brien FJ, Harley BA, Yannas IV, Gibson L. Influence of freezing rate on pore structure in freeze-dried collagen-GAG scaffolds. Biomaterials. 2004;25(6):1077-1086.

27. Alizadeha M, Abbasi F, Khoshfetrat AB, Ghaleh H. Microstructure and characteristic properties of gelatin/chitosan scaffold prepared by a combined freeze-drying/leaching method. Materials Science \& Engineering: C. 2013;33(7):3958-3967.

28. Mao JS, Zhao LG, Yin YJ, Yao KD. Structure and properties of bilayer chitosan-gelatin scaffolds. Biomaterials. 2003;24(6):10671074.

29. Hu L, Wang CA, Huang Y, Sun C, Lu S, Hu Z. Control of pore channel size during freeze casting of porous YSZ ceramics with unidirectionally aligned channels using different freezing temperatures. Journal of the European Ceramic Society. 2010;30(16):3389-3396.

30. Yannas IV. Facts and theories of induced organ regeneration. In: Yannas IV, ed. Regenerative Medicine I: Theories, Models and Methods. Berlin: Springer; 2005. p.1-38.

31. Agrawal CM, Ray BR. Biodegradable polymeric scaffolds for musculoskeletal tissue engineering. Journal of Biomedical Materials Research. 2001;55(2):141-150.

32. Karageorgiou V, Kaplan D. Porosity of 3D biomaterial scaffolds and osteogenesis. Biomaterials. 2005;26(27):5474-91. 